Tema: Solidificação / Lingotamento

\title{
ANÁLISE DE FILMES DE ESCÓRIA DE FLUXANTES PARA AÇOS BAIXO CARBONO*
}

\section{Resumo}

Cláudio Antônio Goulart Valadares ${ }^{1}$ Alexandra de Almeida Diego ${ }^{2}$ Maria Carolina Campello Bezerra ${ }^{3}$ Altemar Dettogne do Nascimento 4 Fernando Vernilli Junior ${ }^{5}$ Sara Carvalho 6

O fluxante para aços baixo carbono, aplicado no lingotamento contínuo de placas, apresenta como características a temperatura de fusão entre $1.030^{\circ} \mathrm{C}$ e $1.070^{\circ} \mathrm{C}$ e a tendência a cristalização suprimida. Desta forma, o filme de escória apresenta predominantemente a fase vítrea que facilita a transferência de calor na interface molde de cobre e pele de aço em solidificação. Há uma tendência em retirar ou reduzir o teor de flúor nos fluxantes, com o objetivo de minimizar a erosão da câmara de exaustão do lingotamento contínuo, além de ser um risco potencial para a saúde e segurança e do aumento da taxa de erosão da válvula submersa. Este trabalho apresenta os resultados de análise dos filmes de escória do fluxante referência e a sua versão isenta de flúor via microscópio eletrônico de varredura e microscópio óptico de luz polarizada. Mais resultados como difratometria de raios- $X$ e análises térmicas também complementam esta análise assim como algumas características físico-químicas dos produtos em questão.

Palavras-chave: Filme de escória; Fluxante para aços baixo carbono.

\begin{abstract}
ANALYSIS OF MOULD FLUX SLAG FILM FOR LOW CARBON STEEL
Abstract

The mould flux for low carbon steels, applied in continuous casting slab machine, has characteristic as the melting temperature between $1,030^{\circ} \mathrm{C}$ and $1,070^{\circ} \mathrm{C}$ and the tendency to crystallization suppressed. Thus, the slag film has predominantly glassy phase which facilitates heat transfer at the interface between cupper mold and the solidifying steel skin. There is a tendency to remove or reduce fluoride content in mould fluxes, in order to minimize the erosion of the exhaustion chamber and continuous casting machine structure, besides being a potential for health and safety hazard and the increase of submerse entry nozzle wear. This paper shows analysis made by scanning electron microscopy and polarized light optical microscopy of slag films applied for this type of steel and the it version fluoride free. More results like diffraction $X$ rays and thermal analysis also complement this analysis as well as some physical and chemical characteristics of the products concerned.

Keywords: Slag film; Mould flux for low carbon steel.
\end{abstract}

1 M.Sc, CQE/ASQ, Engenheiro Metalurgista, Assessoria Estratégica, Carboox Resende Química Ind. Com Ltda, Resende, Rio de Janeiro, Brasil.

2 Engenheira de Materiais, Engenheira de Desenvolvimento de Produto, Carboox Resende Química Ind Com Ltda, Resende, Rio de Janeiro, Brasil

3 Mestre em Engenharia, Engenheira de Produção Química, Vice Presidente, Carboox Resende Química Ind. Com Ltda, Resende, RJ

4 Mestre em Engenharia de Materiais, Especialista Sênior de Lingotamento Contínuo de Placas, ArcelorMittal Tubarão, Serra, Espírito Santo, Brasil

5 Eng. Químico, Ph.D., Coordenador do Programa de Pós-Graduação em Engenharia de Materiais, EEL-USP, Lorena, SP, Brasil.

6 Engenheira Química, EEL-USP, Lorena, SP, Brasil.

\footnotetext{
* Contribuição técnica ao 45 Seminário de Aciaria - Internacional, 25 a 28 de maio de 2014, Porto Alegre, RS, Brasil.
} 


\section{INTRODUÇÃO}

O fluxante consiste em uma mistura de matérias-primas, naturais ou sintéticas, com adição de carbono, que em contato com aço líquido funde e atua conforme cada condição específica de lingotamento. O fluxante é aplicado no processo de Lingotamento Contínuo de Aços em máquinas em que o aço é transferido do distribuidor para o molde através da utilização de válvula submersa, técnica denominada jato protegido. O fluxante é aplicado continuamente sobre o aço líquido na região do molde vazado de cobre refrigerado a água. O seu desenvolvimento leva em consideração o tipo de aço e parâmetros operacionais. De um modo geral, o fluxante pode estar na forma de pó (ou impalpável), pré-fundido ou granulado esférico dependendo da sua forma de fabricação, sendo a última obtida via método Spray Dryer.

As principais funções dos fluxantes são: lubrificar e controlar a transferência de calor na interface molde/pele de aço em solidificação, além de prevenir a reoxidação do aço, absorver inclusões e promover o isolamento térmico sobre o aço líquido no molde. A Figura 1 mostra a forma como o fluxante é aplicado.

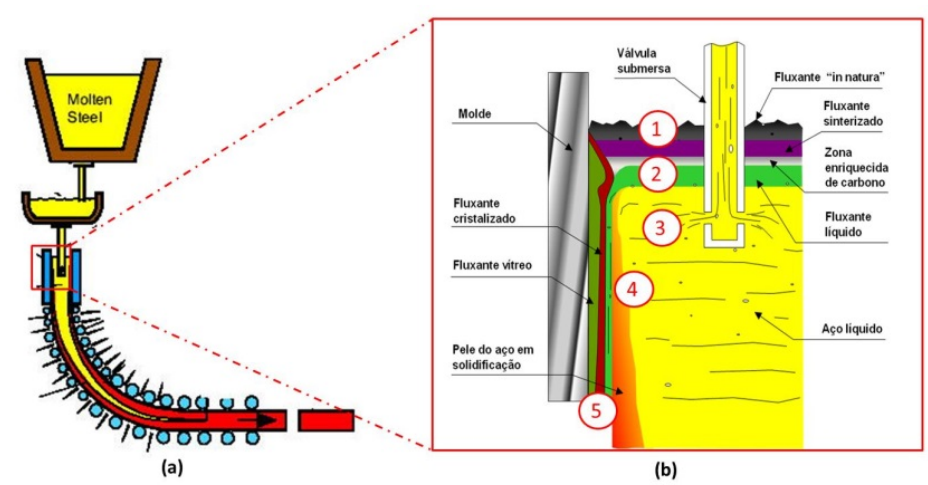

Figura 1. (a) Diagrama esquemático do conjunto panela, distribuidor, molde e pele de aço em solidificação, destacando o molde de lingotamento contínuo. (b) Mostra as camadas que o fluxante forma sobre o molde e na interface molde / pele de aço em solidificação e as respectivas funções enumeradas de 1 a 5, sendo: 1 Isolamento Térmico; 2 Prevenção da Reoxidação; 3 Absorção de Inclusões; 4 Lubrificação e 5 Controle da Taxa de Transferência de Calor (Adaptado da Referência 1).

A composição química do fluxante varia conforme as condições requeridas. Em sua grande maioria, a formação predominante é de tetraedros de $\mathrm{SiO}_{2}$, formando cadeias com viscosidade, taxa de fusão e temperatura de cristalização que podem ser alteradas por:

- Modificadores: $\mathrm{CaO}, \mathrm{MgO}, \mathrm{BaO}, \mathrm{SrO}, \mathrm{Na}_{2} \mathrm{O}, \mathrm{Li}_{2} \mathrm{O}$ e $\mathrm{K}_{2} \mathrm{O}$ que quebram a cadeia de silicato;

- Fluidizantes: $\mathrm{F}^{-}$, que facilmente substitui o oxigênio bivalente resultando na quebra da corrente Si-O e consequentemente diminuem a viscosidade da escória [1-3]; e

- Intermediários: $\mathrm{Al}_{2} \mathrm{O}_{3}$ que mudam de comportamento conforme a matriz.

O flúor representa um papel importante no controle da viscosidade, temperatura de cristalização e fração cristalizada no filme de escória, que contribuem diretamente com a lubrificação. O flúor está presente também na formação da Cuspidina $\left(3 \mathrm{CaO} .2 \mathrm{SiO}_{2} \cdot \mathrm{CaF}_{2}\right)$ que afeta a transferência de calor na interface molde/pele solidificada. Como consequência do uso do flúor, ocorre a formação e emissão de fluoretos, que são significativos para o aumento da acidez da água de refrigeração

\footnotetext{
* Contribuição técnica ao 450 Seminário de Aciaria - Internacional, 25 a 28 de maio de 2014, Porto Alegre, RS, Brasil.
} 
secundária da máquina de lingotamento, favorecendo a erosão e desgaste do equipamento.

Zaitsev et al.[4] realizou experimentos de laboratório e testes industriais com fluxantes contendo flúor e constatou as emissões de $\mathrm{HF}(\mathrm{g})$, fluoretos solúveis (ex. $\mathrm{NaF}$ ) e insolúveis. As Reações 1 a 4 descrevem a emissão de fluoretos como gás.

$$
\begin{array}{ll}
\mathrm{Na}_{2} \mathrm{O}+\mathrm{CaF}_{2}=>2 \mathrm{NaF}(\mathrm{g})+\mathrm{CaO} & \text { (Reação 1) } \\
\mathrm{Al}_{2} \mathrm{O}_{3}+3 \mathrm{CaF}_{2}=>2 \mathrm{AlF}_{3}(\mathrm{~g})+3 \mathrm{CaO} & \text { (Reação 2) } \\
\mathrm{H}_{2} \mathrm{O}+2 \mathrm{CaF}_{2}=>2 \mathrm{HF}(\mathrm{g})+2 \mathrm{CaO} & \text { (Reação 3) } \\
\mathrm{SiO}_{2}+2 \mathrm{CaF}_{2}=>\mathrm{SiF}_{4}(\mathrm{~g})+3 \mathrm{CaO} & \text { (Reação 4) }
\end{array}
$$

Sabe-se que $\mathrm{NaF}(\mathrm{g})$ e $\mathrm{HF}(\mathrm{g})$ são formados em temperaturas acima de $530^{\circ} \mathrm{C}$ e que o $\mathrm{SiF}_{4}(\mathrm{~g})$ e $\mathrm{AlF}_{3}(\mathrm{~g})$ formam em temperaturas mais elevadas. A umidade reage com o flúor de acordo com a Reação 5.

$2 \mathrm{NaF}+\mathrm{H}_{2} \mathrm{O}(\mathrm{g})=>2 \mathrm{HF}(\mathrm{g})+\mathrm{Na}_{2} \mathrm{O}$

Assim, no caso dos fluxantes convencionais para placas, é inevitável que se controle a formação da fase Cuspidina na escória para o controle da transferência de calor horizontal na interface placa/molde. No desenvolvimento de fluxantes sem flúor, a simples substituição de $\mathrm{F}^{-}$por outro fundente ou fluidizante não é suficiente, por isso é necessário uma composição química que, simultaneamente, regule tanto a viscosidade quanto a cristalização da escória [5-9].

O objetivo deste trabalho é comparar e discutir as diferenças físico-químicas dos produtos in natura, assim como as características microestruturais dos filmes de escória, considerando o fluxante de uso industrial (Referência) e da sua versão isenta de flúor (WF), aplicados no lingotamento contínuo de placas em aços baixo carbono. A coleta das amostras dos filmes de escória ocorreu de modo simultâneo, na interface entre o molde e a pele de aço em solidificação, durante sua aplicação no final de um sequencial de 10 corridas. As análises utilizadas para avaliar os filmes de escória foram Difratometria de Raios-X (DRX), Microscopia Eletrônica de Varredura (MEV) e Microscopia Óptica de Luz Polarizada (MO).

\section{MATERIAIS E MÉTODOS}

Primeiramente foram analisados os fluxantes na forma in natura. Os ensaios realizados foram análise química, ensaio de viscosidade em navículas e análise termogravimétrica (DTA). O Ensaio de Navículas é um teste comparativo, sendo que ambos foram inseridos em navículas sobre um refratário e submetidos na temperatura de $1.300^{\circ} \mathrm{C}$ (Figura 2a). Após completa fusão, o refratário foi inclinado em $45^{\circ}$ mantendo a mesma temperatura a fim de comparar as distâncias de escorrimento (Figura $2 b$ ).
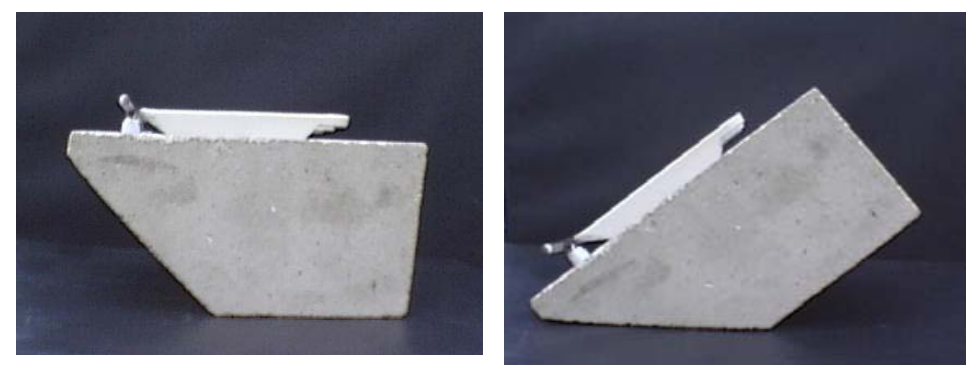

(a)

(b)

Figura 2. Sequencia do Ensaio de viscosidade em navículas_(a) Navículas sobre refratário e (b) após inclinação de $45^{\circ}$.

* Contribuição técnica ao 45 Seminário de Aciaria - Internacional, 25 a 28 de maio de 2014 , Porto Alegre, RS, Brasil. 
Durante a análise térmica as amostras in natura foram submetidas a um programa de aquecimento e resfriamento de $10^{\circ} \mathrm{C} / \mathrm{min}$ onde foram demonstradas as reações exotérmicas e endotérmicas. Mudanças como fusão e solidificação foram registradas sob a forma de picos e variação do fluxo de calor da amostra, registrada como um deslocamento da linha base.

Os filmes de escória foram posteriormente analisados. A coleta das amostras ocorreu durante a aplicação do produto, na mesma máquina de lingotamento contínuo e no final do sequencial de 10 corridas. De modo que a quantidade de fluxante adicionado de cada molde foi neste momento reduzida, o nível de aço diminuiu e o filme de escória naturalmente contraiu. Assim, as amostras foram "pescadas" do molde com o auxílio de um vergalhão em cada veio simultaneamente. Os filmes de escória de cada produto foram caracterizados via difratometria de raios $X$ e microscopias eletrônica de varredura e microscopia óptica.

$\mathrm{Na}$ técnica chamada de difratometria de raios-X, as distâncias interplanares e densidades dos átomos (elétrons) ao longo de cada plano cristalino são características específicas e únicas de cada substância cristalina, assim como o padrão difratométrico por ela gerado, equivalendo a uma impressão digital. A determinação das fases foi feita através da consulta de um banco de dados contendo informações cristalográficas básicas e algumas propriedades físicas de compostos cristalinos. Esta técnica é aplicada com o objetivo de determinar as fases mineralógicas constituintes. Esta é uma das principais técnicas de caracterização microestrutural e consiste na emissão de feixes de elétrons em planos de difração. As amostras foram moídas em almofariz de ágata até obtido $100 \%$ passante na \#200. Foi utilizado o difratômetro Empyrian da Panalytical com o passo angular de $0,013^{\circ}$, tempo de leitura por passo de 100 s e na faixa angular de 10 a $90^{\circ}$.

$\mathrm{Na}$ análise via Microscopia Eletrônica de Varredura (MEV), as amostras dos filmes de escória foram preparadas através do embutimento a frio com resina de cura rápida, evitando assim tensões externas na amostra. A operação de desbaste foi conduzida com lixas de SiC comerciais de 500 a 2400 "mesh". O polimento foi executado com pano de polimento e suspensão de sílica coloidal 0,05 $\mu \mathrm{m}$. Foi necessária a metalização superficial com ouro, pois o material era isolante elétrico sendo assim realizado via sputtering com uma camada de $20 \mathrm{~nm}$, sob vácuo e por 80s. Para esta análise, o microscópio eletrônico de varredura utilizado foi o LEOZeiss, modelo 1450VP. O objetivo da análise foi avaliar a topografia em imagens ampliadas via elétrons secundários e as diferenças de composição química foram avaliadas via elétrons retroespalhados. No Microscópio Óptico (MO) foram utilizadas as mesmas amostras embutidas, porém sem a metalização com ouro, no equipamento Leica modelo-DM IRM. O objetivo foi comparar a diferença de cores das imagens obtidas com o MEV.

\section{RESULTADOS E DISCUSSÃO}

\subsection{Resultados de Análises dos Fluxantes In Natura}

A Tabela 1 mostra a composição química dos fluxantes referência e WF. Foram destacados os percentuais totais dos elementos considerados formadores, modificadores, intermediários e fluidizantes. É evidente a ausência de Flúor no fluxante WF e a diferença de composição química entre eles.

\footnotetext{
* Contribuição técnica ao 450 Seminário de Aciaria - Internacional, 25 a 28 de maio de 2014, Porto Alegre, RS, Brasil.
} 


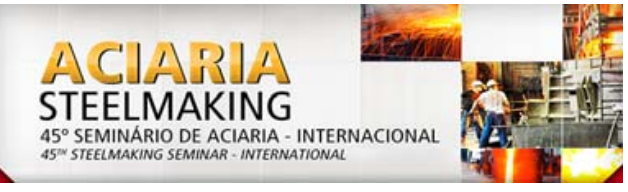

Tabela 1. Composição química dos fluxantes referência e WF

\begin{tabular}{|c|c|c|c|}
\hline \multicolumn{2}{|c|}{ Descrição } & Referência & WF \\
\hline Formadores & $\mathrm{SiO}_{2}+\mathrm{B}_{2} \mathrm{O}_{3}$ & 33,20 & 30,40 \\
\hline Modificadores & $\mathrm{CaO}+\mathrm{Na}_{2} \mathrm{O}+\mathrm{Li}_{2} \mathrm{O}$ & 42,20 & 37,10 \\
\hline Intermediário & $\mathrm{Al}_{2} \mathrm{O}_{3}$ & 3,00 & 7,20 \\
\hline Fluidizante & $\mathrm{F}^{-}$ & 7,20 & 0,00 \\
\hline
\end{tabular}

A Figura 3 mostra o Ensaio de viscosidade em navículas dos fluxantes Referência e WF. É possível observar similaridade de escorrimento em ambos. Outro fato importante é a menor tensão superficial do fluxante WF devido provavelmente à diferença na composição química. Nesta figura foram destacadas em círculos pretos, as diferenças de molhabilidade. Deste modo ao escorrer somente o fluxante WF se espalha pelas laterais da navícula.

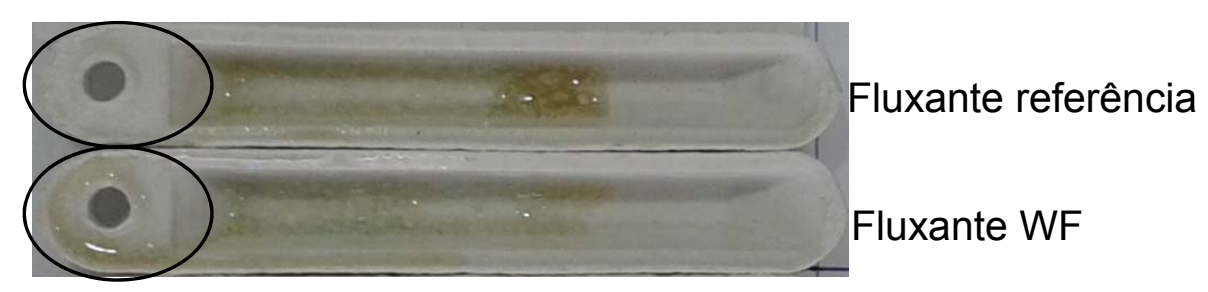

Figura 3. Ensaio de viscosidade em navícula dos fluxantes referência e WF.

Os resultados de Análise Termodiferencial (DTA) no aquecimento dos fluxantes referência e WF são apresentados na Figura 4. Os gráficos mostram similaridade em relação aos picos exotérmicos no intervalo de temperatura entre $400^{\circ} \mathrm{C}$ a $500^{\circ} \mathrm{C}$ devido a decomposição do carbono livre seguido da decomposição dos carbonatos, principalmente carbonato de sódio em ambos, evidenciado pelo posterior pico endotérmico. Outro pico endotérmico está presente no intervalo de $750^{\circ} \mathrm{C}$ a $800^{\circ} \mathrm{C}$ que mostra provavelmente o início da formação de fase líquida. As etapas seguintes que são de amolecimento, fusão e fluidez em ambos que também mostraram similaridade.

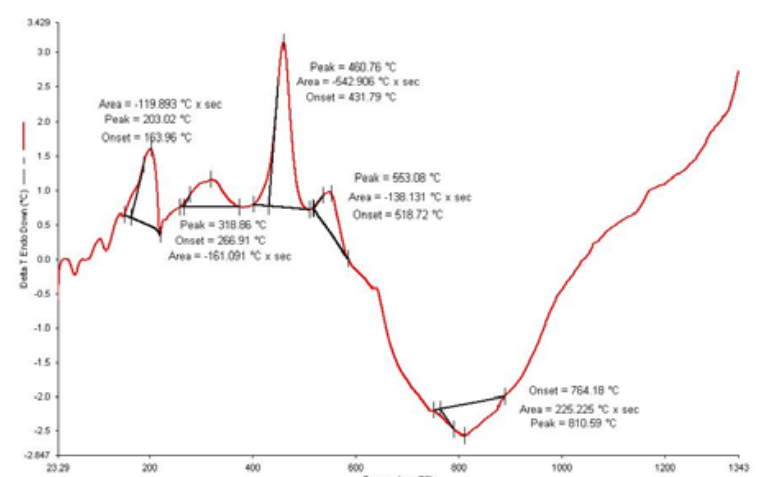

(a)

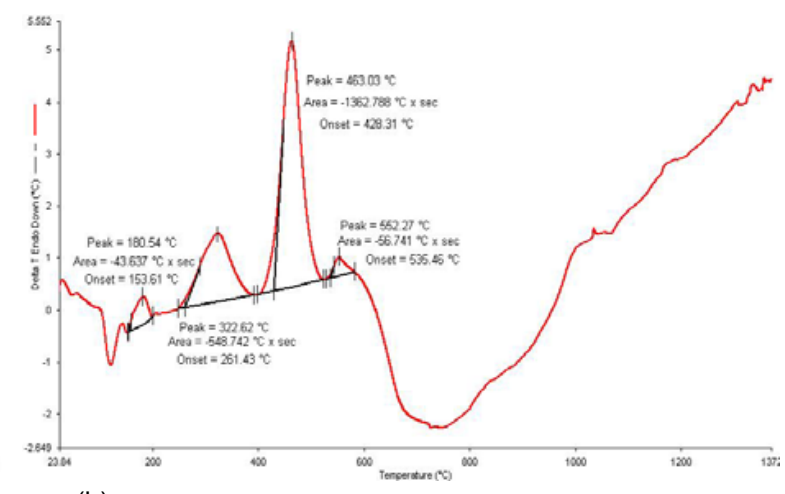

(b)

Figura 4. Resultados de Análise Termodiferencial no aquecimento em (a) fluxante Referência e (b) fluxante WF.

A Figura 5 mostra a Análise Termodiferencial (DTA) durante o resfriamento. Pode-se observar que apenas o fluxante Referência apresentou um pico exotérmico em torno

* Contribuição técnica ao 450 Seminário de Aciaria - Internacional, 25 a 28 de maio de 2014, Porto Alegre, RS, Brasil. 
de $900^{\circ} \mathrm{C}$, característico de Cristalização. Já o fluxante WF não apresentou esta característica.

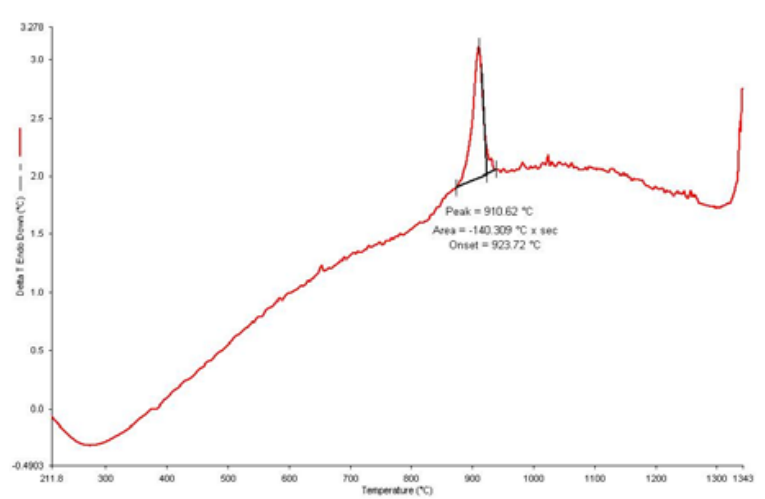

(a) Fluxante Referência

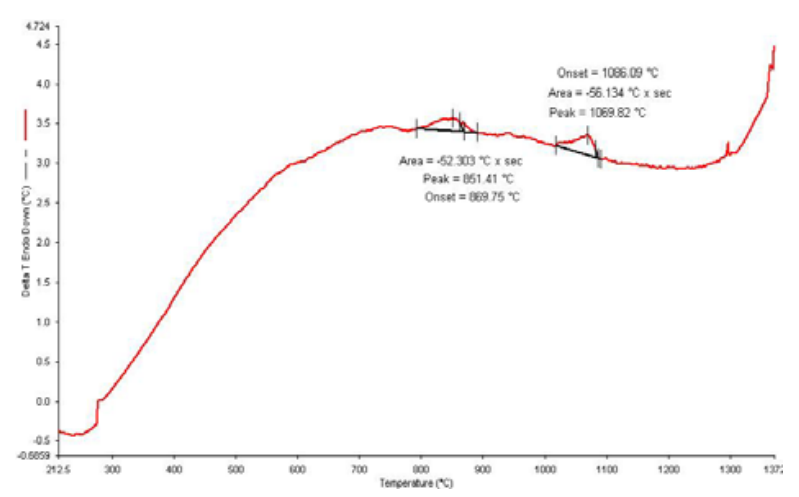

(b) Fluxante WF

Figura 5. Resultados de Análise Termodiferencial no resfriamento em (a) fluxante Referência e (b) fluxante WF.

\subsection{Resultados de Análises dos Filmes de Escória}

O resultado das análises de fases por difratometria de raios- $X$ dos fluxantes referência e WF estão apresentados na Figura 6. Foi possível identificar preferencialmente a fase Cuspidina $\left(3 \mathrm{CaO} .2 \mathrm{SiO}_{2} . \mathrm{CaF}_{2}\right)$ na amostra do filme de escória do fluxante referência, não sendo verificado outras fases presentes. Já na amostra do filme de escória do fluxante WF, não foi possível realizar a identificação de fases devido ao elevado teor de fase amorfa, ou seja, quase ausência de fase cristalina. Em relação à transferência de calor na interface entre o molde de cobre refrigerado a água e placa de aço em solidificação, a presença da fase Cuspidina no filme de escória do fluxante referência irá provavelmente dificultar a transferência de calor, agindo como uma barreira através da difração da radiação. Já a ausência de cristais observada no filme de escória do fluxante WF, irá permitir uma maior condução térmica tanto por radiação quanto por condução.
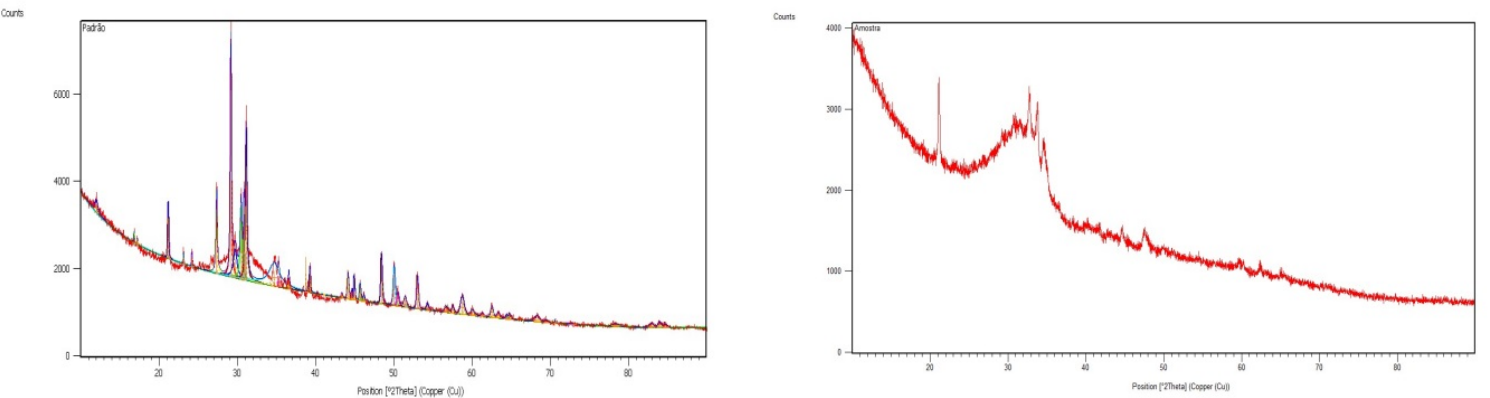

Figura 6. DRX dos fluxantes Referência (gráfico da esquerda) mostrando picos preferencialmente da fase Cuspidina e WF (gráfico da direita), mostrando ausência de fase amorfa.

A Figura 7 mostra os resultados de MEV via elétrons secundários (SE) e Microscopia Óptica (MO). A microscopia realizada via SE tem o objetivo de analisar a topografia da amostra. As Figuras 7a, 7c, 7e e 7g, mostram as seções dos filmes de escória do molde a placa, destacado em círculo preto as respectivas regiões do filme próximo ao molde que apresentou maior desordem. Assim, de um modo geral, tanto no MEV quanto no MO é possível observar a presença de poros em cinza claro no MEV e em

* Contribuição técnica ao 45 Seminário de Aciaria - Internacional, 25 a 28 de maio de 2014, Porto Alegre, RS, Brasil. 
vermelho e amarelo no MO nas proximidades do molde. Já o restante das amostras de ambos se mostrou homogênea principalmente do centro até a face da placa, no MEV devido ao mesmo tom de cinza e no MO devido_a grande parte apresenta a cor verde mais homogênea. Em ambas as técnicas foram possíveis observar coerência nos resultados.

Nas Figuras $7 \mathrm{~b}$ e $7 \mathrm{f}$ de maior ampliação apresentam, em ambos as amostras, bolhas em uma região desordenada mais próximo ao molde. No filme de escória do fluxante referência as bolhas são maiores e em menor número, já no caso do fluxante WF são microbolhas e em maior número. Além disso, existe uma região homogênea entre o interior do filme até o lado da placa, em ambos os filmes. Estas observações são coerentes com a diferença de temperatura existente entre o molde de cobre de $200^{\circ} \mathrm{C}$ e a placa, com aproximadamente $1400^{\circ} \mathrm{C}$. Considerando que maiores temperaturas contribuem com a mobilidade atômica, condição que favorece termodinamicamente a formação de uma região mais homogênea do lado da placa e quanto mais brusca o resfriamento, o material tende a apresentar regiões mais desordenadas similar ao que ocorreu do lado do molde.

É possível correlacionar as imagens obtidas com a tensão superficial observada no ensaio de viscosidade em navículas, pois a maior tensão superficial colabora com o aprisionamento de bolhas que tendem a se coalescer aumentando de tamanho que foi o caso do filme de escória do fluxante referência.

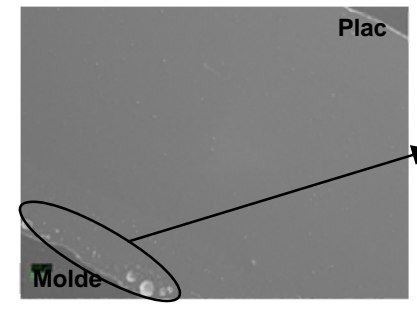

(a) MEV - SE do filme de escória fluxante Referência , ampliação de 130x, WD $11 \mathrm{~mm}, 30 \mathrm{KV}$.

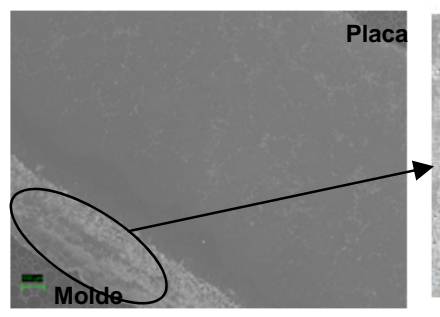

(e) MEV - SE do filme de escória do fluxante WF, ampliação de 130x, WD $11 \mathrm{~mm}, 30 \mathrm{KV}$.

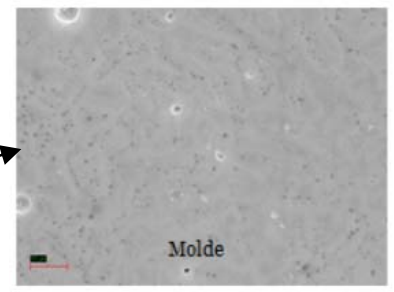

(b) MEV - SE do filme de escória fluxante Referência , ampliação de $3 \mathrm{kx}, \mathrm{WD} 13 \mathrm{~mm}$, $30 \mathrm{KV}$.

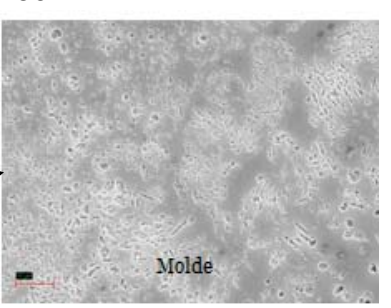

(f) MEV - SE do filme de escória do fluxante WF, ampliação de 3kx, WD $13 \mathrm{~mm}, 30 \mathrm{KV}$.

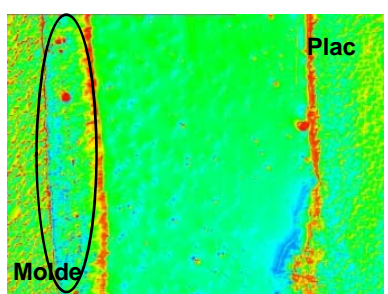

(c) MO do filme de escória do fluxante Referência , 500micro, ampliação de 50x.

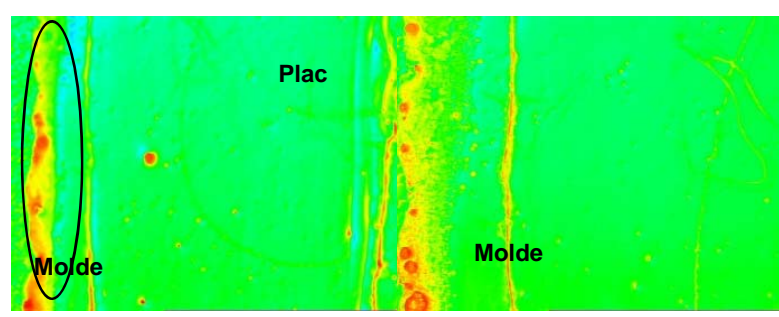

(g) MO do filme de escória do fluxante WF, 500micro, ampliação de $50 x$.

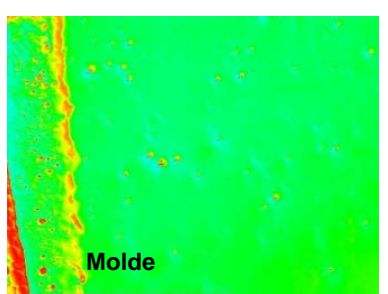

(d) MO do filme de escória do fluxante Referência , 200micro, ampliação de 100x.

(h) MO do filme de escória do fluxante WF, 200micro, ampliação de $100 x$.

Figura 7. Imagens do filme de escória do fluxante Referência: (a) e (b) MEV - SE e em (c) e (d) MO. Imagens do filme de escória do fluxante WF: Figuras (e) e (f) MEV - SE e em (g) e (h) MO.

A Figura 8 mostra a análise do MEV via elétrons retroespalhados (BSD) com o objetivo de mostrar as diferenças de composição química elementar. As Fguras 8a e $8 b$ são do filme de escória do fluxante referência e $8 c$ e $8 d$ do fluxante WF. Quanto mais clara a região na imagem maior o peso atômico do elemento que constitui a amostra e o contrário, quanto mais escura a imagem, mostra regiões de menor peso atômico. É importante ressaltar que a presença de bolhas, indicados com círculo

* Contribuição técnica ao 45 Seminário de Aciaria - Internacional, 25 a 28 de maio de 2014, Porto Alegre, RS, Brasil. 
preto, já foram identificada nas análises anteriores via elétrons secundários e ainda assim estão presentes nas imagens da via BSD. Observa-se na Figura 8a que o fluxante referência apresenta uma composição homogênea, fato coerente com o respectivo resultado de DRX, que mostrou a presença da fase Cuspidina. Enquanto que o fluxante WF apresenta imagens com maior homogeneidade composicional, novamente coerente com seu DRX, que apresentou alto teor de fase amorfa. As letras de a até I nas Figuras $8 \mathrm{a}$ e 8c, correspondem da região da placa até o molde e foram indicadas ao longo de cada amostra para a realização das pontuais via WDS.

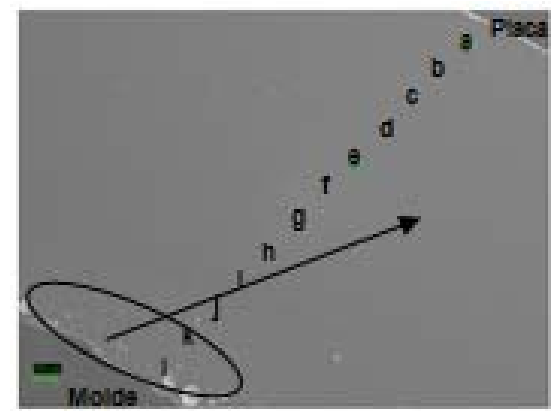

(a) MEV - BSD do filme de escória do fluxante Referência , ampliação 130x, WD $11 \mathrm{~mm}, 30 \mathrm{KV}$.

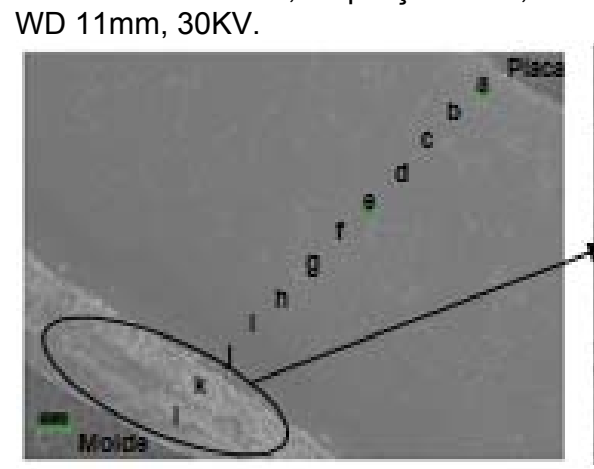

(c) MEV - BSD do filme de escória do fluxante WF, ampliação de 130x, WD $11 \mathrm{~mm}, 30 \mathrm{KV}$

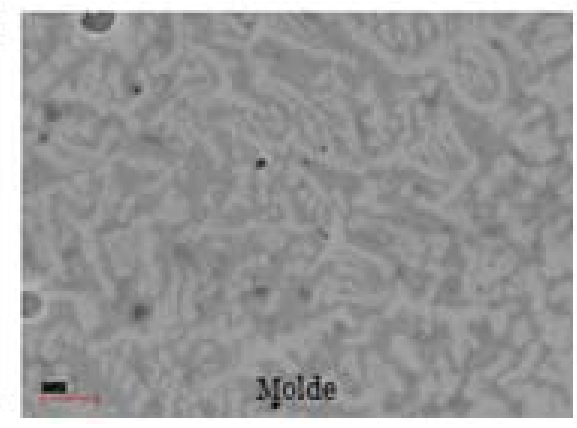

(b) MEV - BSD do filme de escória do fluxante Referência , ampliação $3 \mathrm{kx}$, WD $13 \mathrm{~mm}, 30 \mathrm{KV}$.

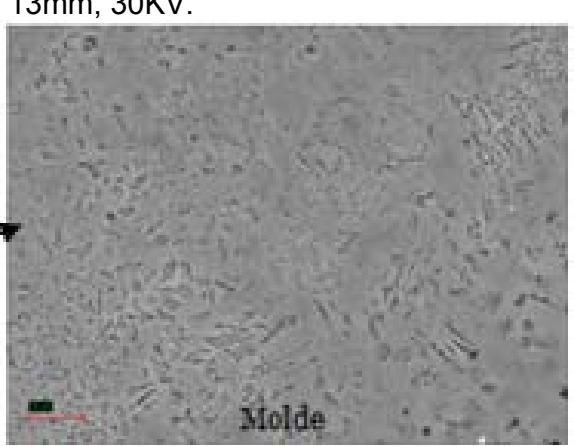

(d) MEV - BSD do filme de escória do fluxante WF, ampliação de 3kx, WD $16 \mathrm{~mm}, 30 \mathrm{KV}$

Figura 8. Imagens de MEV realizados via elétrons retroespalhados (BSD). Nas Figuras (a) e (c) as letras ao longo do filme de escória indicam as análises pontuais elementares. Resultados do filme de escória do fluxante referência: Figuras (a) e (b) e do fluxante WF: Figuras (c) e (d).

Os gráficos da Figura 9a a 9j mostram as tendências de composições químicas elementares via WDS. Dos gráficos citados, o teor de Alumínio apresentou diferença significativa entre os fluxantes, coerente com os valores de composição química dos produtos in natura, que no fluxante referência era de 3,0\% e no WF de 7,2\%. Podese associar o maior teor de alumínio presente nos filmes de escória, provavelmente, a absorção de inclusões durante a sua aplicação.

\footnotetext{
* Contribuição técnica ao 45 Seminário de Aciaria - Internacional, 25 a 28 de maio de 2014 Porto Alegre, RS, Brasil.
} 


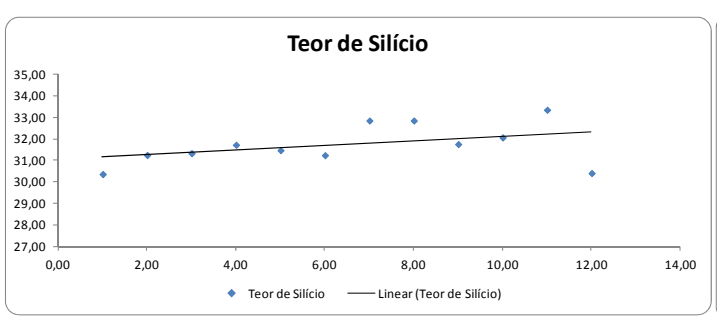

(a) Teor de Silício Fluxante referência

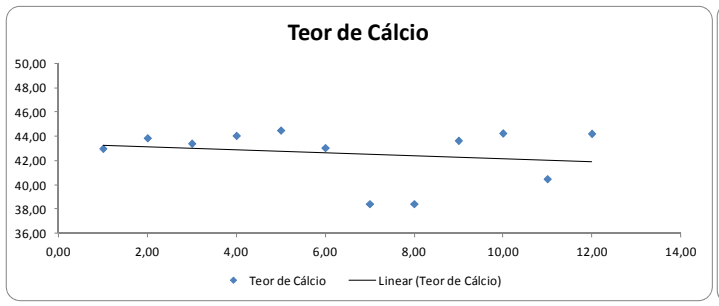

(c) Teor de Cálcio Fluxante referência

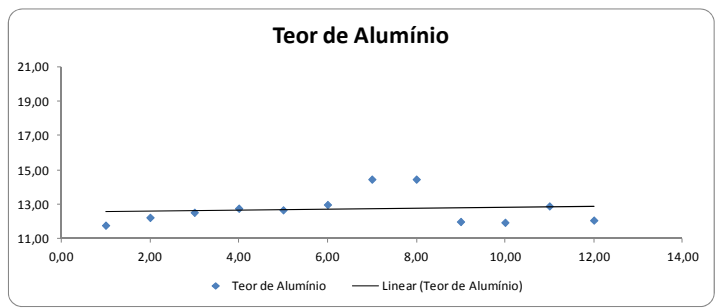

(e) Teor de Alumínio Fluxante Referência

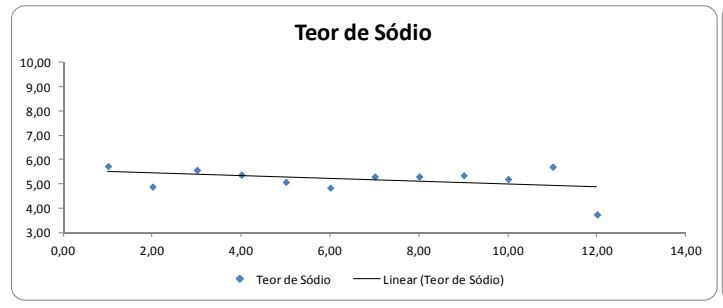

(g) Teor de Sódio Fluxante Referência

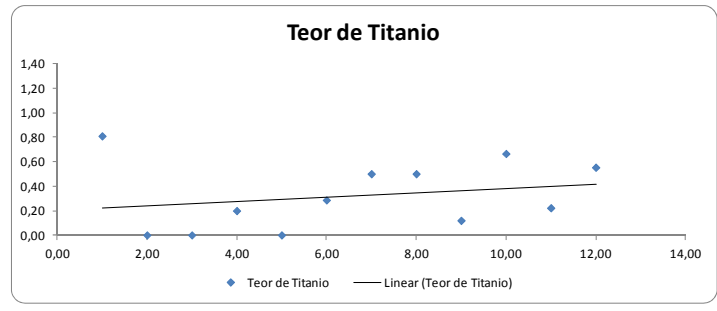

(i) Teor de Sódio Fluxante Referência

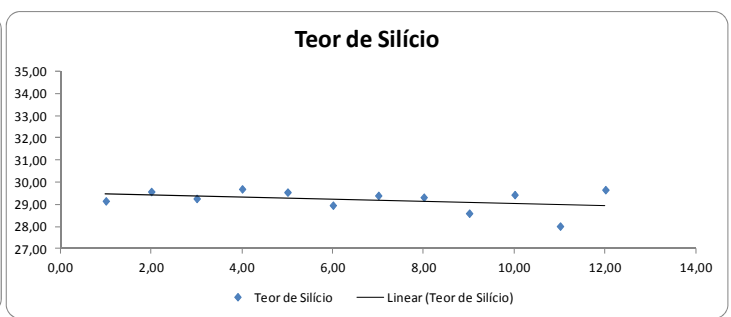

(b) Teor de Silício Fluxante WF

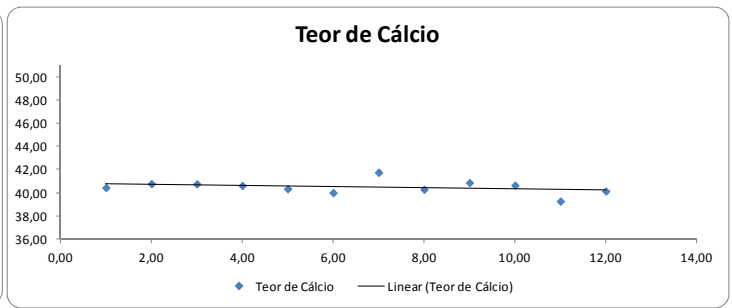

(d) Teor de Cálcio Fluxante WF

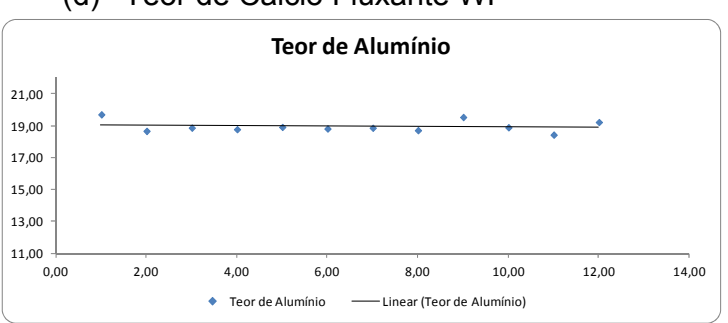

(f) Teor de Alumínio Fluxante WF

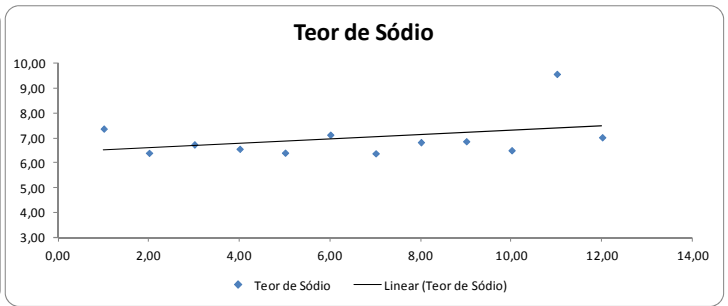

(h) Teor de Sódio Fluxante WF

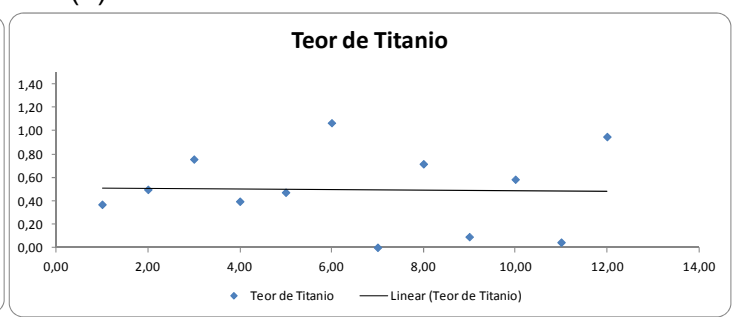

(j) Teor de Sódio Fluxante WF

Figura 9. Gráficos de (a) até (j) ilustrando as análises pontuais via WDS dos fluxantes Referência lado esquerdo e WF lado direito, mostrando as linhas de tendência em cada caso. Os pontos da esquerda para a direita equivalem às análises elementares das seções dos filmes de escórias da placa ao molde.

\section{CONCLUSÕES}

Através dos resultados obtidos foi possível concluir que:

- No ensaio de viscosidade em navículas ambos os fluxantes in natura apresentaram escorrimento similar, sendo o fluxante WF visualmente com menor tensão superficial provavelmente devido a diferenças na composição química;

* Contribuição técnica ao 45 Seminário de Aciaria - Internacional, 25 a 28 de maio de 2014, Porto Alegre, RS, Brasil. 
- Apesar de valores diferentes de análise química, ambos os fluxantes in natura apresentaram picos endotérmicos e exotérmicos similares no DTAaquecimento;

- No DTA-resfriamento a versão in natura do fluxante WF não mostrou a ocorrência de reações, diferente do fluxante referência que apresentou pico exotérmico característico de formação de cristais a $900^{\circ} \mathrm{C}$. Coerente com o DRX do filme de escória do fluxante WF que apresentou elevado teor de fase amorfa e com o fluxante referência que apresentou a fase Cuspidina;

- As análises via MEV - SE e MO dos filmes de escória foram coerentes. Sendo que no filme de escória do fluxante referência foi verificada a presença de bolhas grandes e em menor número. Já no fluxante WF, foram observadas microbolhas e em número significativo. Esse fato foi relacionado com a diferença na tensão superficial observado no ensaio de viscosidade em navículas, que no fluxante WF foi visualmente menor que no fluxante referência;

- $\mathrm{Na}$ análise via MEV (SE) e MO, em ambos os filmes de escória, foram encontrados próximo ao molde a presença de uma região desordenada e próxima a placa uma região mais homogênea. Este fato foi coerente com as imagens via MEV (BSD) que mostraram praticamente o mesmo tom de cinza do centro dos filmes até o lado da placa;

- Apesar das análises microestruturais e dos resultados de DRX dos fluxantes analisados apresentarem algumas diferenças, foi possível utilizar o fluxante isento de flúor em um sequencial em 10 corridas, provavelmente porque o desempenho está associado a um conjunto de características e não somente a diferença delas individualmente.

\section{REFERÊNCIAS}

1 Fox A, Mills, Lever K D, Bezerra C, Valadares C, Unamuno I, Laraudogoitia J, Gisby J. Development of fluoride-free fluxes for billet casting. ISIJ Int. 2005;45(7):1051.

2 Pinheiro CA, Samarasekera IV, Brimacombe JK. Mould flux for continuous casting of steel - Part I e II. Iron and Steelmaker. ISS; October 1994. v.62, p.55-56.

3 Fox AB, Valdez ME, Gisby J, Atwood RC, Lee PD, Sridhar S. Dissolution of ZrO2, $\mathrm{Al} 2 \mathrm{O} 3, \mathrm{MgO}$ and MgAl2O4 Particles in a B2O3 Containing Commercial Fluoride-free Mould Slag. ISIJ Int. 2004;44(5):836-845.

4 Zaitsev AI, Leites AV, Litvina AD, Mogutnov BM. Investigation of the mould powder volatiles during continuous casting. Steel Research. 1994;65:368.

5 Zhang Z, Wen G, Zhang Y. Crystallization Behavior of F-free Mold Fluxes. ISIJ Int. 2011;18(2):150.

6 Wen G, Sridhar S, Tang P, Qi X, Liu Y. Development of fluoride-free mold powders for peritectic steel slab casting. ISIJ Int. 2007;47(8):1117-25.

7 Qi X, Wen G, Tang P. Investigation on heat transfer performance of fluoride-free and titanium-bearing mold fluxes. Journal of Non-Crystalline Solids. 2008;354(52-54):544452.

8 Campello MC B. Avaliação do efeito do carbono em fluxantes para lingotamento contínuo de aços [Tese de mestrado]. São Paulo: Universidade de São Paulo; 2006.

9 Diego AA, Bezerra MCC, Valadares CAG, Barrios SR, Gomes NF, Sá MLS, et al. Influência do fluxante na redução do desgaste de válvula submersa no molde de lingotamento contínuo. In: ABM. $41^{\circ}$ Seminário de Aciaria - Internacional; 2010; Resende, Brasil. São Paulo: ABM; 2010.

* Contribuição técnica ao $45^{\circ}$ Seminário de Aciaria - Internacional, 25 a 28 de maio de 2014, Porto Alegre, RS, Brasil. 